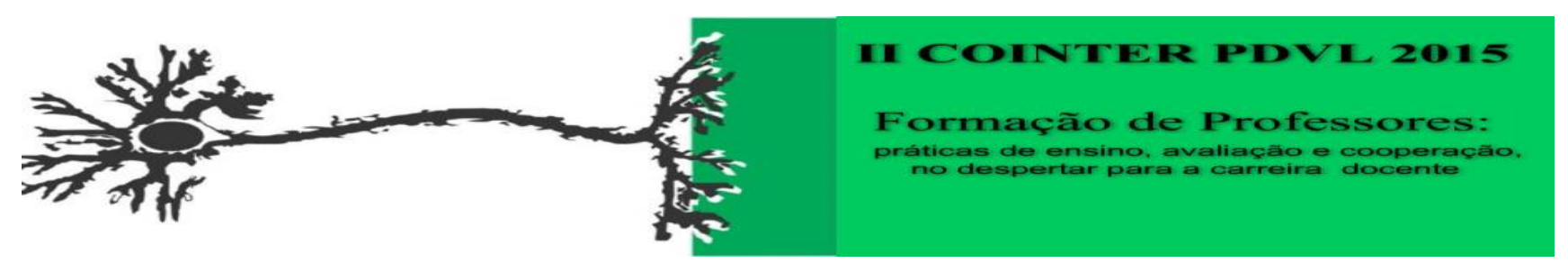

\title{
PROGRAMA DE FORMAÇÃO EMPREENDEDORA PARA EXCELÊNCIA NA ATUAÇÃO PROFISSIONAL
}

\author{
Bianca Tamairy Fabricio* e Emanuella Petruska Ataíde Silva, Discente, Instituto Federal de Educação, \\ Ciência e Tecnologia de Pernambuco, Estrada do Alto do Moura, KM 3,8, Distrito Industria III, Caruaru - PE, \\ Brasil \\ Ana Carolina Peixoto Medeiros, docente, Instituto Federal de Educação, Ciência e Tecnologia de \\ Pernambuco, CEP Caruaru - PE
}

\section{RESUMO}

O programa de formação empreendedora para excelência na atuação profissional é necessário para uma formação exigida pelo mercado de trabalho. Esse estudo teve como objetivo desenvolver ações que auxiliam os jovens a iniciar sua carreira profissional bem mais preparados. Com base nas definições de competência profissional, tendo em foco as ideologias de estudiosos dessa área - e nas pesquisas realizadas - foi elaborado um questionário para definir se os alunos estão capacitados para o mercado de trabalho, sendo comparado com o quadro de competência de cada curso técnico profissional ofertado no IFPE - Campus Caruaru. Tendo por fim, o objetivo de fazer com que o aluno contribua com a obtenção dos dados, fornecendo informações de como melhorar sua formação profissional. O estudo chegou à conclusão que a formação acadêmica apenas não é suficiente para uma atuação no mercado com profissionalismo e visão de crescimento. Tanto os alunos quanto os empresários apontaram para a necessidade de capacitação e melhoria quanto à formação profissional desses jovens.

PALAVRAS-CHAVE: Empreendedorismo. Competência. Formação Profissional. Mercado de Trabalho.

Pesquisa.

\begin{abstract}
The entrepreneurial training program for excellence in professional performance is required for a training required by the labor market. This study aimed to develop actions that help young people start their professional career much better prepared. Based on the professional competence of the definitions in focus ideologies of scholars in this area - and in studies - a questionnaire was designed to determine whether students are trained for the labor market, being compared with the competency framework for each course in IFPE, center Caruaru. Having finally, in order to make the student contributes to obtaining the data, providing information on how to improve their professional training. The study came to the conclusion that education alone is not enough for a performance in the market with professionalism and vision of growth. Both the students and entrepreneurs pointed to the need for training and improvement as the training of these young people.
\end{abstract}

KEYWORDS: Entrepreneurship. Competence. Vocational Training. Labor Market. Search.

\section{Introdução}


O programa de formação empreendedora para excelência na atuação profissional surge da necessidade de uma formação mais alinhada com as exigências do mercado de trabalho quanto à postura profissional, proatividade, apresentação pessoal e demais atitudes pertinentes ao tema.

Educar com princípios empreendedores e voltados a uma formação de caráter organizacional se faz presente hoje em todas as escolas e currículos. Essa formação condiz com as inúmeras dificuldades que os estudantes e a sociedade como um todo apresenta quanto ao início de sua vida profissional e a todos os desafios encontrados nessa jornada.

É importante salientar que dentro das ações e práticas docentes está a questão da matriz curricular, suas competências e direcionamentos com base nos saberes propostos aos alunos. A formação dos professores e suas experiências são mais que relevantes a esse contexto. Outra função importante é a adequação empreendedora dessa matriz curricular e seus direcionamentos com a formação ao mercado de trabalho. Todo esse cenário depende da atuação docente e de sua formação.

Assim, essa pesquisa sobre educação profissional é concebida como um caminho que busca aproximar a realidade mercadológica e a formação presente na vida dos jovens estudantes, sendo estruturada através de uma grade curricular atualizada e voltada aos saberes do relevantes a pratica profissional. Através da formação desses jovens e de suas aspirações essa pesquisa buscou identificar as necessidades do mercado de trabalho quanto às dificuldades, dúvidas, medos, e desafios existentes para essa melhor formação quanto à postura e comportamento profissional.

Por vezes a formação educacional que se recebe nas escolas se direciona quase em sua totalidade conteudisticamente. Dessa maneira os alunos ficam distantes do universo do trabalho e todas as suas nuances, exigências e aspirações. Deixando-os assim inseguros e amedrontados quanto ao comportamento mais adequado, mais exitoso, menos comprometedor. São tantas as dúvidas, que a elaboração de um currículo pode se tornar um tormento.

Com base no exposto este trabalho tem como objetivo desenvolver ações que auxiliem numa melhor percepção da comunidade acadêmica e social quanto ao mundo do trabalho, suas exigências, complexidades e desafios; gerando dessa maneira profissionais bem mais preparados.

\section{Fundamentação Teórica}

Nas organizações, a palavra competência denota vários sentidos, alguns relacionados ao indivíduo e outros à tarefa (resultados).

No início dos anos 90, Prahalad e Hammel, em Competindo para o Futuro, introduziram na gramática empresarial a expressão competência essencial (core competence), despertando o interesse 
nos meios acadêmicos e organizacionais do mundo inteiro, mostrando que as empresas bemsucedidas e extremamente competitivas, eram mais que portfólios de negócios, eram portfólios de competências. O foco desses autores é nas competências coletivas. O argumento é o de que obterão mais sucesso no mundo corporativo as organizações que souberem identificar e desenvolver as competências que serão necessárias para obter vantagem competitiva.

Para Prahalad e Hamel (1990), uma competência só pode ser considerada essencial se passar por três testes:

$\checkmark$ Valor percebido pelos Clientes: Uma competência essencial deve permitir a uma empresa agregar valor de forma consistente e diferenciada a seus clientes.

$\checkmark$ Diferenciação entre Concorrentes: uma competência essencial deve diferenciar a empresa de seus competidores. Precisa ser algo percebido no mercado como específico da marca.

$\checkmark$ Capacidade de Expansão: uma competência essencial deve abrir as portas do futuro para a empresa. Ela não pode ser só a base para os produtos e serviços atuais. Ela deve sustentar novos serviços e produtos.

No nosso projeto, a ideia é fortalecer os envolvidos gerando diferenciais nos mesmos quanto a formação de competências comportamentais que gerem maior impacto na sua atuação profissional. Parry (apud PINCHOT, 1999, p.126) define competência como:

$$
\begin{aligned}
& \text { Um agrupamento de conhecimentos, habilidades e atitudes } \\
& \text { correlacionados. Que afeta parte considerável da atividade de alguém, que } \\
& \text { se relaciona com o desempenho, que pode ser medido segundo padrões } \\
& \text { preestabelecidos, e que pode ser melhorado por meio de treinamento e } \\
& \text { desenvolvimento. }
\end{aligned}
$$

É importante ressaltar como este autor relaciona competência com o desempenho do indivíduo, do grupo e da organização.

Ao definir competência, Zarifian (apud BRANDÃO, 1999) parte do pressuposto de que num ambiente dinâmico e competitivo não é possível considerar o trabalho como apenas um conjunto de tarefas a serem desempenhadas estática e mecanicamente. Para este autor, conforme figura 1 abaixo, competência significa: "assumir responsabilidades frente a situações de trabalho complexas, permitindo ao profissional lidar com eventos inéditos, surpreendentes e de natureza singular".

\section{Figura 1: Competências de uma Organização}




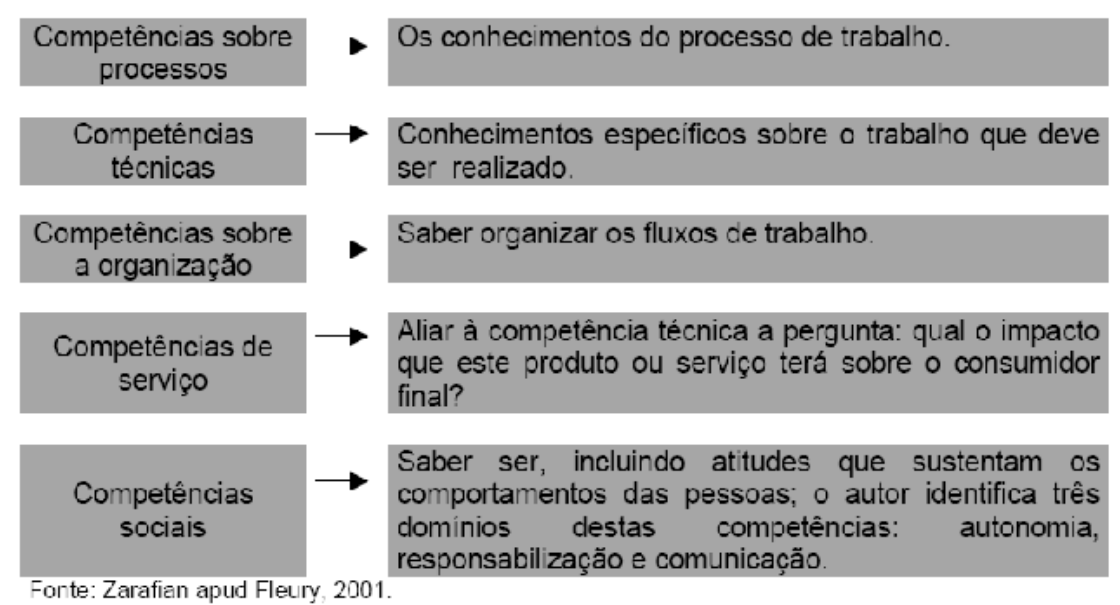

Durand (apud BRANDÃO, 2001) concebeu um conceito de competência baseado em três dimensões - conhecimento, habilidade e atitude - como mostra a Figura 2.

Figura 2: As três dimensões da competência

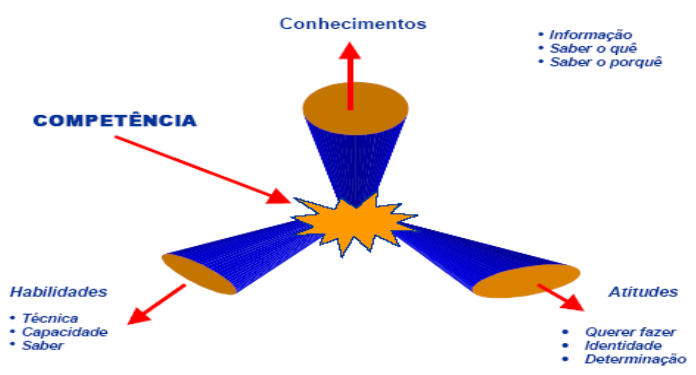

Fonte: Durand, 2000 adaptado

Considerando estas três dimensões como interdependentes ao expor uma determinada habilidade, pressupõe-se que o indivíduo tenha domínio e qualificação técnica para exercê-la e que adote atitudes favoráveis e positivas.

Importante registro deve ser feito neste momento sobre o que é o conhecimento e como ele surge. A resposta a esta pergunta vem ocupando a mente de filósofos e estudiosos ao longo de toda a história da humanidade, sem que se consiga chegar a uma definição consensual. Ora as teorias empiristas procuram confirmar a possibilidade e a origem do conhecimento privilegiando o objeto, ora as teorias racionalistas destacarão o sujeito como fonte ou condição do processo de conhecimento. Perante esta tensão epistemológica, alguns autores procurarão conciliar o sujeito e o objeto, privilegiando a relação entre eles.

Conforme mencionado por Resende (2000, p.36), "quem tem mais conhecimento é, potencialmente, mais competente, mas se tornar efetivamente competente implica colocar o conhecimento em prática de forma a alcançar objetivos, obter resultados”. 
Essa distinção se baseia em Michael Polanyi (apud NONAKA e TAKEUCHI, 1997, p.65) segundo a qual "o conhecimento tácito é pessoal, específico ao contexto e difícil de ser formulado e comunicado. Já o conhecimento explícito ou codificado refere-se ao conhecimento transmissível em linguagem formal e sistemática".

O conhecimento tácito inclui elementos cognitivos e técnicos. Os elementos cognitivos incluem os modelos mentais e, juntamente com os esquemas, paradigmas, perspectivas, crenças e pontos de vista, ajudam os indivíduos a perceberem e definirem seu mundo. Ropé e Tanguy (1997, p.17) discorrem sobre o tema levantando a hipótese de que não se trata de modismo e de que "[...] A noção de competência é uma dessas noções, testemunho de nossa época".

Nesse sentido ainda os autores Ropé e Tanguy (1997, p.17) argumentam que: “[...] O caráter extensivo e duradouro do uso de uma noção demonstra um certo número de mudanças em uma sociedade que devem ser identificadas".

Observa-se em Barbosa (1994) que o conceito de competência está intimamente relacionado à ideia de laboralidade, ampliando ainda mais a responsabilidade das instituições de ensino e de trabalho, na medida em que exige, dentre outros, novas formas de organização do trabalho, incorporação de conhecimento e de metodologias que propiciem o desenvolvimento de novas competências. Partindo dessa ideia de laboralidade é que nosso projeto se constrói. Ele é focado ao universo laboral, não obstante com foco em uma formação comportamental, que dentro da teoria sobre Competências caminha sobre os conteúdos atitudinais.

Fortalecer atitudes e direcioná-las a práticas profissionais é reduzir os riscos de insucesso e frustrações nesse ambiente de mudança constante e exigências mercadológicas complexas.

\section{Metodologia}

A pesquisa possui uma metodologia aplicada, sendo a mesma descritiva e exploratória. A aplicação se refere ao fato de atuação direta com os envolvidos em projetos de capacitação e formação profissional. Para que essa atuação prática seja formatada, foi necessária uma investigação sobre as carências, necessidades e possibilidades do universo profissional dos estudantes e sociedade envolvida no processo.

O processo metodológico pode ser desenhado da seguinte forma:

1- Estudo sobre as necessidades do mercado e suas demandas;

2- Mapeamento das necessidades e carências dos alunos quanto a essas demandas profissionais;

3- Mapeamento através de pesquisa das necessidades e dificuldades dos empresários nos processos de seleção e avaliação do perfil comportamental profissional dos jovens em sua 
atuação no mercado;

4- Alinhamento das exigências mercadologias com a formação encontrada dos alunos, através do programa de fortalecimento das competências comportamentais envolvidas no processo;

Essa pesquisa é de caráter exploratório e descritivo. A pesquisa exploratória e descritiva é considerada muito útil para o estabelecimento de suas premissas teóricas, possibilitando assim uma aproximação conceitual. Porém a análise empírica, que objetiva analisar a teoria versus à realidade, pressupõe o desenho de um modelo conceitual que fundamente o estudo.

Este modelo conceitual produzido nesse estudo foi produto de uma revisão profunda da literatura, bem como de um levantamento junto aos alunos dos cursos subsequentes de Segurança do Trabalho, Edificações e Mecatrônica, do IFPE Campus Caruaru. Fora os alunos dos cursos subsequentes, também foram estudadas as demandas dos alunos do curso superior em Engenharia Mecânica, também da mesma instituição. Professores foram consultados sobre como elaboram a grade curricular e suas competências. Outra fonte de dados foram 10 empresas da região do Agreste Pernambucano, onde 7 se concentram na cidade de Caruaru e as 3 restantes na cidade de Santa Cruz do Capibaribe.

\section{Análise dos Dados}

Com base na literatura e nos projetos pedagógicos, fornecidos pelo IFPE - Campus Caruaru, foi desenvolvido um quadro de competências com cada curso do existente campus, contendo os conhecimentos, habilidades e atitudes (CHA'S) que cada aluno deve obter ao final da sua formação. Abaixo nos quadros 1, 2, 3 e 4 são apresentados os esboços desse modelo conceitual produzido:

\section{Bacharelado em Engenharia Mecânica}

\begin{tabular}{|l|l|l|}
\hline \multicolumn{3}{|c|}{ BACHARELADO EM ENGENHARIA MECÂNICA } \\
\hline \multicolumn{1}{|c|}{ Conhecimento } & \multicolumn{1}{|c|}{ Habilidade } & \multicolumn{1}{|c|}{ Atitudes } \\
\hline $\begin{array}{l}\text { Trabalha em projetos, montagem, } \\
\text { fabricação, manutenção, programação e } \\
\text { operação de sistemas mecânico, de } \\
\text { automação e robótica industrial; }\end{array}$ & $\begin{array}{l}\text { A Habilidade de manter uma } \\
\text { abordagem teórica sólida para } \\
\text { permitir a introdução de novas } \\
\text { tecnologias }\end{array}$ & $\begin{array}{l}\text { Criativo, particularmente no } \\
\text { processo de design; }\end{array}$ \\
\hline $\begin{array}{l}\text { Nas indústrias, os profissionais podem } \\
\text { trabalhar na fabricação de equipamentos, } \\
\text { peças, produtos de conformação, soldagem, } \\
\text { usinagem e fundição; }\end{array}$ & $\begin{array}{l}\text { Habilidade de Usar uma ampla } \\
\text { variedade de ferramentas, } \\
\text { técnicas e equipamentos } \\
\text { (incluindo software) adequados } \\
\text { à sua disciplina específica; }\end{array}$ & Auto motivado; \\
\hline
\end{tabular}




\begin{tabular}{|l|l|l|l|}
\hline $\begin{array}{l}\text { Trabalha com sistemas térmicos de } \\
\text { produção de energia e climatização; } \\
\text { atividades de planejamento, manutenção e } \\
\text { gestão de operações; atividades técnico } \\
\text { comerciais; }\end{array}$ & $\begin{array}{l}\text { Habilidade de Promover, } \\
\text { desenvolver e aplicar sistemas } \\
\text { de segurança do trabalho; }\end{array}$ & $\begin{array}{l}\text { Analítico na formulação e } \\
\text { soluções de problemas; }\end{array}$ \\
\hline $\begin{array}{l}\text { Desenvolve processos assistidos por } \\
\text { computador; }\end{array}$ & $\begin{array}{l}\text { A Habilidade de avaliar e } \\
\text { gerenciar riscos; }\end{array}$ & $\begin{array}{l}\text { Inovador, na solução de } \\
\text { problemas de engenharia; }\end{array}$ \\
\hline
\end{tabular}

Quadro 1 - Quadro de Competências do Bacharelado em Engenharia Mecânica

FONTE: Elaborada pelos autores

\section{Curso Técnico em Edificações (Subsequente)}

\begin{tabular}{|l|l|l|}
\hline \multicolumn{1}{|c|}{ EDIFICAÇÕES } \\
\hline \multicolumn{1}{|c|}{ Conhecimento } & \multicolumn{1}{|c|}{ Habilidade } & \multicolumn{1}{c|}{ Atitude } \\
\hline $\begin{array}{l}\text { Desenvolve e executa projetos de } \\
\text { edificações conforme normas técnicas de } \\
\text { segurança e de acordo com legislação } \\
\text { específica; }\end{array}$ & $\begin{array}{l}\text { Habilidade de interpretar e } \\
\text { desenvolver projetos de } \\
\text { edificações; }\end{array}$ & $\begin{array}{l}\text { Ter postura profissional e } \\
\text { ética; }\end{array}$ \\
\hline $\begin{array}{l}\text { Planeja a execução e elabora orçamento de } \\
\text { obras; }\end{array}$ & $\begin{array}{l}\text { Habilidade de Coordenar e } \\
\text { fiscalizar as etapas de execução } \\
\text { de obras de edificações; }\end{array}$ & Resolver problemas; \\
\hline $\begin{array}{l}\text { Presta assistência técnica no estudo e } \\
\text { desenvolvimento de projetos e pesquisas } \\
\text { tecnológicas área de edificações; }\end{array}$ & $\begin{array}{l}\text { Habilidade de Desenvolver } \\
\text { treinamentos; }\end{array}$ & Auto Motivação; \\
\hline $\begin{array}{l}\text { Orienta e coordena a execução de serviços } \\
\text { de manutenção de equipamentos e de } \\
\text { instalações em edificações; }\end{array}$ & $\begin{array}{l}\text { Habilidade de elaborar textos } \\
\text { técnicos, planilhas, formulários, } \\
\text { esquemas gráficos; }\end{array}$ & $\begin{array}{l}\text { Disposição para tentar, o que } \\
\text { não foi tentado antes; }\end{array}$ \\
\hline $\begin{array}{l}\text { Orienta na assistência técnica para compra, } \\
\text { venda e utilização de produtos e e } \\
\text { equipamentos especializados. }\end{array}$ & $\begin{array}{l}\text { Habilidade de estabelecer } \\
\text { comunicação interpessoal. }\end{array}$ & Empatia. \\
\hline
\end{tabular}

Quadro 2 - Quadro de Competências do Curso Técnico em Edificações (Subsequente)

FONTE: Elaborada pelos autores

\section{Curso Técnico em Mecatrônica (Subsequente)}

\begin{tabular}{|l|l|l|}
\hline \multicolumn{1}{|c|}{ MECATRÔNICA } \\
\hline \multicolumn{1}{|c|}{ Conhecimento } & \multicolumn{1}{|c|}{ Habilidade } & \multicolumn{1}{c|}{ Atitude } \\
\hline $\begin{array}{l}\text { Atua no projeto, execução e instalação de } \\
\text { máquinas equipamentos automatizados e } \\
\text { sistemas robotizados; }\end{array}$ & $\begin{array}{l}\text { Habilidades no manuseio de } \\
\text { ferramentas e acessórios } \\
\text { utilizados em automação; }\end{array}$ & Possuir iniciativa; \\
\hline $\begin{array}{l}\text { Realiza manutenção, medições e testes } \\
\text { dessas máquinas, equipamentos e sistemas } \\
\text { conforme especificações técnicas; }\end{array}$ & $\begin{array}{l}\text { Habilidade de integrar equipes } \\
\text { de elaboração e execução de } \\
\text { projetos de sistemas } \\
\text { automatizados; }\end{array}$ & Senso de responsabilidade; \\
\hline $\begin{array}{l}\text { Programa e opera essas máquinas, } \\
\text { observando as normas de segurança. }\end{array}$ & $\begin{array}{l}\text { Habilidade de orientar e er capaz de adaptar-se às } \\
\text { coordenar sistemas de produção. }\end{array}$ & $\begin{array}{l}\text { Ser cánas tecnológicas e } \\
\text { mudanças texigências do mercado. } \\
\text { exiado }\end{array}$ \\
\hline
\end{tabular}

Quadro 3 - Quadro de Competências do Curso Técnico em Mecatrônica (Subsequente)

FONTE: Elaborada pelos autores

\section{Curso Técnico em Segurança do Trabalho (Subsequente)}

\begin{tabular}{|l|l|c|}
\hline \multicolumn{3}{|c|}{ SEGURANÇA DO TRABALHO } \\
\hline \multicolumn{1}{|c|}{ Conhecimento } & \multicolumn{1}{|c|}{ Habilidades } & Atitudes \\
\hline $\begin{array}{l}\text { Compreensão da legislação e normas } \\
\text { técnicas relativas à Segurança do Trabalho; }\end{array}$ & $\begin{array}{l}\text { Habilidade de Interpretação de } \\
\text { plantas, desenho e croqui; }\end{array}$ & Poder de decisão; \\
\hline
\end{tabular}




\begin{tabular}{|c|c|c|}
\hline $\begin{array}{l}\text { Desenvolve ações educativas na área de } \\
\text { saúde e segurança do trabalho; }\end{array}$ & $\begin{array}{l}\text { Habilidade de planejamento em } \\
\text { estabelecer critérios para a } \\
\text { escolha de equipamentos de } \\
\text { proteção individual; }\end{array}$ & Compromisso; \\
\hline $\begin{array}{l}\text { Orienta o uso de Equipamentos de Proteção } \\
\text { Individual (EPI) e Equipamentos de } \\
\text { Proteção Coletiva (EPC); }\end{array}$ & $\begin{array}{l}\text { Habilidade de avaliação dos } \\
\text { riscos profissionais a que estão } \\
\text { expostos os trabalhadores e as } \\
\text { formas de prevenção de } \\
\text { acidentes de trabalho; }\end{array}$ & Ética; \\
\hline $\begin{array}{l}\text { Executa programas de prevenção de riscos. } \\
\text { Investiga, analisa acidentes e recomenda } \\
\text { medidas de prevenção e controle; }\end{array}$ & $\begin{array}{l}\text { Habilidade de Comunicação } \\
\text { com os funcionários para } \\
\text { realização de treinamentos e } \\
\text { DDS; }\end{array}$ & Flexibilidade; \\
\hline $\begin{array}{l}\text { Conhecer os Planos de Controle de } \\
\text { Emergência e de Ajuda Mútua. }\end{array}$ & $\begin{array}{l}\text { Habilidade de pró- ativa para } \\
\text { reconhecer os fatores de riscos } \\
\text { ambientais. }\end{array}$ & Foco/Disciplina. \\
\hline
\end{tabular}

Quadro 4 - Quadro de Competências do Curso Técnico em Segurança do Trabalho (Subsequente)

FONTE: Elaborada pelos autores

Com base no quadro de competências, foram elaborados quatro questionários, sendo uma para cada curso, com perguntas objetivas e uma pergunta aberta. Nesse questionário, foram alvos alunos do $3^{\circ}$ ao $4^{\circ}$ período dos cursos de Edificações, Mecatrônica e Segurança do Trabalho, já do Bacharelado em Engenharia Mecânica, foram entrevistados alunos do $3^{\circ}$ ao $6^{\circ}$ período.

A partir das informações coletadas por meio deste questionário, foi realizada uma análise dos dados, tendo em vista as competências empreendedoras dos alunos.

\section{Resultados}

\section{Bacharelado em Engenharia Mecânica}

Foram entrevistados treze alunos do Bacharelado em Engenharia Mecânica do IFPECampus Caruaru, com a finalidade de saber se eles possuem características necessárias para formação de um bom profissional, presente nos quadros de competências, que são: motivação, habilidade, criatividade, competência, proatividade, inovação, compromisso e atitude ambiental. Os dados mostram que a grande maioria dos alunos (77\%) possuem seis ou mais características - total ou em parte - sendo importante para realização profissional, sendo as maiores fortalezas motivação e proatividade. E uma pequena parte $(23 \%)$ alega não ter quatro ou menos características, sendo criatividade e habilidade as maiores fraquezas.

Em seguida foi proposta uma questão para que o aluno pudesse dar motivos para que uma empresa possa contrata-lo. Grande parte das respostas foram voltadas a questões curriculares, como cursos de línguas, projetos extracurriculares, etc. Sendo mais importante um currículo recheado do que a preocupação em realmente ser um bom profissional, propriamente dito. Enquanto apenas uma pequena parte citou vagamente algumas características do quadro de competências. Dos treze alunos entrevistados, quatro optaram por não responder à questão. 


\section{Curso Técnico em Edificações (Subsequente)}

No curso subsequente de técnico de Edificações, foram entrevistados vinte e um alunos, aos quais tinham que responder se possuíam as características necessárias do quadro de competência do curso, que são: Competência, proatividade, determinação, ética, atitude, inovação, conhecimento técnico, motivação e habilidade. A grande maioria dos alunos $(81 \%)$ possuem sete ou mais características - total ou em parte - sendo habilidade e ética as maiores fortalezas. O que é de extrema importância para o futuro como um bom profissional. Enquanto uma pequena parcela (19\%) não possui três ou menos características, sendo a maior deficiência em inovação.

A questão proposta aos vinte e um alunos do curso de Técnico em Edificações teve a finalidade de entender os objetivos a curto e longo prazo na área de atuação desejada. A resposta de todos os alunos, quanto ao objetivo a curto prazo, foi de terminar o curso. Quanto a longo prazo grande parte dos alunos pretendem começar um curso superior nas áreas de engenharia e arquitetura, sendo muito proveitoso, pois iniciará a vida acadêmica superior com uma bagagem teórica avançada, facilitando o ingresso e a permanência no curso, formando futuramente um ótimo profissional. E apenas uma pequena parte deseja permanecer com o nível técnico e continuar trabalhando na área. Dos vinte e um alunos, quatro optaram por não respondem a questão.

\section{Curso Técnico em Mecatrônica (Subsequente)}

No curso subsequente de Técnico em Mecatrônica quinze alunos foram entrevistados, com a finalidade de saber se possuíam as características do quadro de competência do curso proposto, que são: Liderança, conhecimento, mudança, habilidade, responsabilidade, proatividade, atitude e trabalho em equipe. A maior parcela dos alunos (87\%) possui sete ou mais características - total ou em parte - do quadro de competência, sendo responsabilidade a maior fortaleza. Sendo muito importante para o futuro profissional de cada um, e das empresas contratantes. E uma pequena parte (13\%) não possui duas ou menos características, sendo habilidade a maior deficiência.

Foi proposta a questão de indicar motivos que uma empresa teria para contratar os alunos do curso Técnico em Mecatrônica. Todos os alunos seguiram o mesmo viés, afirmando possuir as qualidades essenciais de um bom profissional, também presente no quadro de competência do curso. Dos quinze alunos, cinco optaram por não responder à questão.

\section{Curso Técnico em Segurança do Trabalho (Subsequente)}

Vinte alunos foram entrevistados no curso subsequente de Técnico em Segurança do Trabalho. A pesquisa teve a finalidade de compreender se os alunos possuem as características 
necessárias para ser um bom profissional, presente no quadro de competência do curso, que são: Ética, habilidade, atitude, relação interpessoal, disciplina, conhecimento, compromisso e proatividade. Grande parte dos alunos $(75 \%)$ possuem sete ou mais características - total ou em parte - do quadro de competência, tendo atitude, proatividade e compromisso como as fortalezas. Sendo um resultado muito positivo para o porvir de cada futuro profissional. A minoria dos alunos (25\%) não possuem duas ou menos características, sendo conhecimento a maior fraqueza.

A questão dada aos alunos, objetiva entender se o aluno conhece a área de atuação do curso e o que ele faz para se destacar no mercado de trabalho. Todos os alunos entendem bem a área de atuação do curso, sabem o que um técnico de segurança do trabalho faz, e compreendem também que para se destacar no mercado de trabalho é preciso estar sempre atualizado em questões teóricas e sempre em busca de qualificações, para que as empresas possam visa-lo e ambos tenham a ganhar. Dos vinte alunos, cinco optaram por não responder.

Os resultados apresentados segundo Parry (apud PICARELLI, 1999, p.126) expressam um agrupamento de conhecimentos, habilidades e atitudes correlacionados que afeta parte considerável da atividade dos alunos. Esse resultado se relaciona com o desempenho, que pode ser medido segundo padrões preestabelecidos, e que pode ser melhorado por meio de treinamento e desenvolvimento com relação ao desenvolvimento dos jovens para o mercado de trabalho. Os resultados mostram também, concordando com Resende (2000), que quem detém o conhecimento é mais competente, e para se tornar efetivamente competente é necessário botar esse conhecimento em prática.

Um ponto bastante negativo desses dados é a deficiência em inovação dos alunos, para Prahalad e Hamel (1990) uma competência essencial para uma empresa agregar valor de forma consistente é a diferenciação, de forma positiva, de outras empresas, dessa maneira seria essencial a capacidade de criatividade e inovação por parte dos alunos. Barbosa (1994) disse que para a formação de um bom profissional, a instituição de ensino tem que agir diretamente com os alunos, exigindo novas formas de organização de trabalho, incorporação de conhecimentos e metodologias que assegurem o desenvolvimento de competências. O que é realmente de extrema importância, uma vez que, a instituição agindo as deficiências findarão.

Os resultados fortalecem o argumento de Barbosa ( 1994) que fala sobre laboralidade. Esse conceito é focado ao universo laboral, com foco em uma formação comportamental, que dentro da teoria sobre Competências caminha sobre os conteúdos atitudinais. 
Ou seja, fortalecer atitudes e direcioná-las a práticas profissionais gera redução dos riscos de insucesso e frustrações nesse ambiente de mudança constante e exigências mercadológicas complexas.

As dez empresas entrevistadas apresentaram dados bastante significativos. Como o perfil das mesmas foi heterogêneo podemos comparar os resultados apenas pelos perfis de competências gerenciais e não técnicas.

Das empresas entrevistadas 4 são da área comercial. Dentre as respostas, encontramos que $60 \%$ trazem que falta aos alunos no inicio da vida profissional uma postura de mercado. A pesquisa mergulhou nessa expressão para entender o que realmente significa essa carência. Após novas investigações, chegamos a conclusão que "postura de mercado" para os empresários dessa segmento comercial é, visão de futuro, compromisso com a tarefa, responsabilidade com as tomadas de decisão, ter iniciativa, assumir riscos, entender uma dinâmica de trabalho em equipe e o que nos chamou atenção também foi, vestir-se adequadamente e se comunicar com linguagem apropriada.

Esse resultado corrobora com a ideia de que fortalecer os envolvidos gerando diferenciais nos mesmos quanto a formação de competências comportamentais geram maior impacto na sua atuação profissional.

Ao definir competência, Zarafian (apud BRANDÃO, 2001) parte do pressuposto de que num ambiente dinâmico e competitivo não é possível considerar o trabalho como apenas um conjunto de tarefas a serem desempenhadas estática e mecanicamente. Para este autor, competência significa: “assumir responsabilidades frente a situações de trabalho complexas, permitindo ao profissional lidar com eventos inéditos, surpreendentes e de natureza singular".

Segundo outras empresas investigadas, falta aos alunos nesse inicio de vida profissional, conhecimentos gerenciais. Também no propósito de entender mais sobre essa expressão, vinculamos a mesma ao quadro formulado através da pesquisa e a conclusão foi que , esses conhecimentos gerenciais são vistos como conhecimentos sobre marketing, interesse dos clientes, empatia, postura proativa e abertura para novos conhecimentos.

Segundo Prahalad e Hamel (1990), uma competência só pode ser considerada essencial se passar pelos testes de valor percebido pelos Clientes, diferenciação entre Concorrentes e capacidade de Expansão. Para o alcance desses propósitos dominar os conhecimentos gerenciais são de valiosa garantia. 
Dessa maneira percebemos que dentro da proposta dos cha's, as variáveis atitudinais e de habilidades se sobressaem ao conhecimento especificamente. Isso demonstra que o mercado espera jovens dispostos ao aprendizado, que busquem novos conhecimentos, mas que assumam responsabilidades, sejam curiosos, criativos e ousados nesse processo. Não esperem que tudo chegue fácil, mas se arrisquem, procurem, queiram evoluir.

Podemos sintetizar os resultados da pesquisa com as empresas, da seguinte forma:

$\checkmark$ Os alunos chegam ao mercado de trabalho com conhecimentos específicos, porém não com conhecimentos gerenciais.

$\checkmark$ Comportamento proativo também foi citado entre $80 \%$ das empresas, que afirmam que os alunos em formação, chegam ao mercado sem postura de iniciativa.

$\checkmark$ Relações Interpessoais foram citadas por $70 \%$ empresas. Problemas de relacionamento provocados por aspectos de imaturidade e descompromisso com as tarefas.

$\checkmark$ Comunicação e ética profissional foram aspectos generalizados por $100 \%$ das empresas. As Empresas estudadas, apontam que os recém contratados ou estagiários não desenvolvem essa habilidade e esta atitude. Problemas com brincadeiras, uso excessivo de redes sociais e fofocas depreciativas são relatos dos empresários e gerentes.

$\checkmark$ Falta de planejamento de carreira. Essa habilidade foi apresentada por $40 \%$ das empresas. Indicando que os jovens trabalham sem visão de futuro. Não reagem as necessidades das empresas. Pensam apenas em feriados, mas não estão disponíveis para cursos e novos treinamentos.

O que se torna um ponto negativo para os recém formados, pois como disse (ZARIFIAN, 2001), o desafio das organizações passou a ser a formação de equipes auto gerenciadas, capazes de assumir iniciativas, promover mudanças e aperfeiçoar produtos e processos. Assim, as competências dos colaboradores vêm ganhando dimensão cada vez mais abrangente e as tradicionais metas financeiras tendem a ser substituídas por estratégias não-lineares que, por sua vez, dependem cada vez mais das competências individuais dos trabalhadores.

Ressalta-se nesse resumo que o papel docente na construção de movimentos empreendedores e voltados a uma formação complementar é de suma importância.

\section{Considerações Finais}


Essa pesquisa desenvolveu uma reflexão sobre quais capacidades são relevantes aos jovens que estão em formação para iniciar sua vida profissional com segurança e menor risco. Além de gerar uma reflexão sobre a importância na elaboração das matrizes curriculares e sobretudo do trabalho de formação docente envolvido.

Essas "capacidades" foram tratadas como "competências individuais" e analisadas na perspectiva dos discentes e dos empresários na tentativa de fortalecer os resultados e a compreensão da abordagem, devido à importância da mesma no processo de apreensão do conhecimento e conseqüente formação humana, profissional e cidadã dos alunos.

A temática das competências vem sendo estudada há cerca de 30 anos (Medeiros, 2007), perpassando por inúmeros conceitos e contradições quanto ao seu entendimento. Existem estudos para competências essenciais (core competences), técnicas, comportamentais, enfim, uma gama de vertentes que buscam cada vez mais aglutinar a essência da temática numa perspectiva nuclear.

O trabalho desenvolvido nesse artigo caminhou sob a ótica das competências individuais para atuação profissional e empreendedora dos jovens estudantes . E, sob esse olhar descobriu novas percepções para o constructo em questão.

Percebeu-se que atitudes como empatia, senso de responsabilidade, iniciativa, ousadia são fundamentais na visão das empresas, ultrapassando inclusive as questões dos conhecimentos específicos. Para os jovens estudantes, em sua grande maioria habilidades como planejamento, comunicação, domínio da execução das atividades solicitadas são muito importantes. Todas essas competências podem ser desenvolvidas mediadas por um professor. Daí a importância do mesmo construir essas práticas em sala de aula e fortalecer relações que gerem esses frutos.

De uma forma geral evidenciou-se uma gama de competências individuais, através da construção do modelo de competências por cursos que fortalece a percepção e o senso profissional dos alunos quanto a necessidade que o mercado vem tendo e as limitações que apenas a formação acadêmica vem gerando. Ou seja, realmente se faz necessário uma formação complementar que supra as carências de um conhecimento gerencial e de formação de mercado capaz de diminuir as distancias entre o aluno em formação e as expectativas do mercado profissional.

\section{Referências}

BARBOSA, Luís (1994), O Papel da Formação Profissional para uma gestão participada dos recursos humanos, in Organização e Trabalho, n.12. Outubro de 1994, pp.32-52. 
BRANDÃO, Hugo Pena. Gestão baseada nas competências: um estudo sobre competências profissionais na indústria bancária. Dissertação (Mestrado em Administração), Universidade de Brasília - UNB, 1999.

DURAND, T. Stratezing for innovation: competence analysis in assessing strategic change. In: Competence-based strategic management. Edited by Ron Sanchez and Aimé Heene. Chichester, England: John Wiley \& Sons, 1997.

GIL, Antônio Carlos. Como elaborar projetos de pesquisa. 3.ed. São Paulo: Atlas, 2002

NONAKA, I \& TAKEUCHI, H. Criação do conhecimento na empresa. Rio de Janeiro: Campus, 1997.

PINCHOT, G. Organização inteligente usa toda capacidade de seus funcionários. SP: Folha Management, anexo da Folha. de São Paulo, 22 de janeiro de 1999, p.126.

PRAHALAD, C.K. \& HAMEL, Gary. The core competence of the corporation. Harvard Business Review, Boston, p. 79-91, May-June, 1990.

e RAMASWAMY, V. Como incorporar as competências dos clientes. HSM Management, São Paulo, n. 20, p. 42-52, mai/jun.2002.

RESENDE, Enio. O livro das competências: desenvolvimento das competências: a melhor auto ajuda para pessoas, organizações e sociedade. Rio de janeiro, Qualitymark, 2000.

ROPÉ, Françoise \& TANGUY, Lucie. Introdução. In: Saberes e competências: o uso de tais

noções na escola e na empresa. Organizado por Françoise Ropé \& Lucie Tanguy. Campinas: Papirus, p. 15-24, 1997. 